\title{
Comunicação breve As tutelas de urgência na judicialização da saúde e a medicina baseada em evidências
}

\author{
Brief communication \\ Injunctions on health judicialization and evidenced-based medicine \\ Comunicación breve \\ Tutelas urgentes en la judicialización de la salud y la medicina basada en la evidencia
}

Luiz Marcelo Cabral Tavares ${ }^{1}$

\begin{abstract}
Resumo
O presente ensaio tem por objetivo abordar o tema da judicialização da saúde, mais especificamente do deferimento de tutelas de urgência; o uso da medicina baseada em evidências como alternativa para arrefecimento dessa crise institucional; e fomentar o debate em torno de propostas viáveis para minimizar os impactos deletérios da judicialização sobre a gestão do sistema de saúde.
\end{abstract}

Palavras-chave: Judicialização da saúde. Medicina baseada em evidências. Direito à saúde. Poder Judiciário.

\section{Abstract}

This essay aims to address the issue of judicialization of health, more specifically the granting of emergency relief; the use of evidence-based medicine as an alternative to alleviate this institutional crisis; and foster debate around viable proposals to minimize the deleterious impacts of judicialization on health system management.

Keywords: Judicialization of health. Evidence-based medicine. Right to health. Judicial power.

\section{Resumen}

Este ensayo tiene como objetivo abordar el tema de la judicialización de la salud, más específicamente la concesión de ayuda de emergencia; el uso de medicina basada en evidencia como una alternativa para aliviar esta crisis institucional; y fomentar el debate sobre propuestas viables para minimizar los efectos nocivos de la judicialización en la gestión del sistema de salud.

Palabras clave: Judicialización de la salud. Medicina basada en la evidencia. Derecho a la salud. Poder Judicial.

\section{Introdução}

A Constituição da República Federativa do Brasil (CRFB), de 1988, em seu artigo 196,

\footnotetext{
${ }^{1}$ Procurador do Estado de Minas Gerais; mestre em Direito Processual pela UERJ, Rio de Janeiro, RJ, Brasil. E-mail: Imct@uol.com.br.
} 
enunciou a saúde como direito de todos e dever do Estado (1). O Texto Magno também afirmou que nenhuma lesão ou ameaça a direito seria excluída da apreciação do Poder Judiciário. Em paralelo, o Código de Processo Civil (CPC), no artigo 300, preconiza que "a tutela de urgência será concedida quando houver elementos que evidenciem a probabilidade do direito e o perigo de dano ou o risco ao resultado útil do processo" (2). Propiciou-se, assim, combinação perfeita para uso de toda sorte de demandas judiciais tendentes ao fornecimento de fármacos e insumos de uso medicinal, ademais, em caráter liminar.

De outro lado, descurou-se - diante da repetição de demandas e do quase imposto produtivismo quantitativo judicial - do uso da medicina baseada em evidências (3), que é usar, servir-se, conscientemente, da melhor evidência atual para a tomada de decisões sobre o cuidado do paciente. Secundarizou-se medida alternativa e mais próxima de nossa realidade, consistente em compartilhamento de riscos (4), quando do deferimento de tutelas provisórias.

Com o quadro que se vem propor, procurar-se-á fomentar o debate no sentido de que a falta do uso de evidência na medicina ou alternativa à medida incrementa significativa e negativamente a judicialização da saúde, fenômeno que praticamente nulifica as iniciativas dos gestores em saúde.

\section{Breves considerações sobre a tutela de urgência}

A concessão da tutela de urgência se funda na probabilidade de existência do direito e no perigo de dano decorrente da demora na concessão da tutela requerida ou risco para o resultado útil do processo.

A despeito de a mencionada probabilidade não se fundar em cognição exauriente, que é aquela desenvolvida para a decisão de mérito, deve consistir em razoável suporte probatório no sentido da existência do direito. É a compreensão que se extrai do magistério da jurisprudência, conforme Agravo Interno (Aglnt) no Agravo em Recurso Especial (AREsp) no 1442211/GO, de relatoria do Ministro Marco Aurélio Belizze, do Superior Tribunal de Justiça (STJ) (5). Em paralelo, deve ficar demonstrado o perigo de dano decorrente da demora na concessão da tutela requerida ou risco para o resultado útil do processo.

Focando, por ora, no requisito consistente na probabilidade da existência do direito, há que se ter em mente que, para além da demonstração de início de prova para a 
concessão da tutela requerida em caráter liminar, toda e qualquer decisão proferida no bojo do processo há que se dar por fundamentação analítica (6), que é aquela mais abalizada, mais profunda, cercada de argumentos cuja autoridade a sustentará diante de razoável crivo. A falta de referida fundamentação, sob a égide do Código de Processo Civil (2) em vigor, artigo 11, acarreta a nulidade, já que elevada à condição de norma fundamental do processo civil, reproduzindo, outrossim, norma de magnitude constitucional, como se vê do artigo 93, IX, da Constituição da República (1). O CPC em vigor adotou, assim, a Teoria do Direito Processual Constitucional (7), já que passa a ser disciplinado de acordo com os valores constitucionais, que possuem carga normativa. Para que não haja eventual alegação de sujeição a valores cujo grau de abstração não garantiria adequada tipificação, reitera-se o teor do artigo 11 do CPC (2) e artigo 93, IX, da Constituição Federal (1).

É assim que a prova para o fornecimento de fármacos ou insumos medicinais, ainda que em estágio de mera delibação (para concessão de liminares), deve se basear em alguma evidência científica e efetiva probabilidade de se arrostar a patologia que acomete 0 demandante. Nesse contexto, importante destacar que a tutela de urgência comporta revogação ou modificação, nos termos dos artigos 296, 304, § 6oㅡ, e 1.015, I, todos do CPC (2). Analisemos, dessarte, alguns tópicos acerca da medicina baseada em evidências.

\section{Noções básicas sobre a medicina baseada em evidências}

Nos dias 02 a 05 de julho de 2019, aconteceu, em Brasília, DF, o XXXV Congresso Nacional de Secretarias Municipais de Saúde (Conasems), evento que oportunizou, dentre outros importantes congêneres, o seminário denominado Judicialização da Saúde em Debate.

No seminário, Gustavo dos Santos Fernandes - diretor-geral do Hospital Sírio Libanês, unidade de Brasília, e presidente da Sociedade Brasileira de Oncologia Clínica (SBOC) - abordou os temas de pesquisa clínica e medicina baseada em evidência, cujas principais conclusões serão apresentadas a seguir. Como maior desafio da temática proposta, apresentou-se indagação sobre qual seria a evidência mais apropriada. Para se chegar à resposta, constaram como indicadores referenciais o número crescente de publicações sobre a evidência apresentada e o processo de construção e validação de referida evidência. 
O conceito formulado anteriormente de que a medicina baseada em evidência seria usar, servir-se, conscientemente, da melhor evidência atual para a tomada de decisões sobre o cuidado do paciente, seria traduzido em: a) usar tratamentos mais efetivos e menos danosos; b) substituir tratamentos; c) estabelecer padrões metodológicos; d) avaliar tecnologias em saúde; e) fomentar profissionais a manter a prática; e f) estimular o aumento de qualidade.

Como definidor ou, ao menos, o principal definidor da evidência, foi trazido à baila o ensaio clínico ou estudo clínico randomizado (clinical trial), que é passível de aplicação a medicamentos, prevenção etc. Foi proposto, sempre de maneira sistêmica, uma metodologia para o estudo clínico randomizado, com as seguintes fases: a) fase 1: trata-se a segurança da droga; b) fase 2: testa-se o funcionamento da droga; c) fase 3: compara-se a terapia padrão com a nova, verificando-se o ganho (foi dito que, nessa fase, o custo é de "centenas de milhões de dólares"); d) pós-marketing: efeitos danosos e marketing propriamente dito (mencionou-se que essa fase é de fundamental e particular importância).

O palestrante fechou o debate relatando que a incorporação rápida não significa incorporação qualificada e que há que se "pensar fora da caixa": a) há a necessidade de evolução no processo de aprovação das drogas; b) há necessidade de utilização de novos modelos de clinical trial; c) o Brasil precisa de deixar de ser só consumidor; e d) processo de incorporação de drogas precisa ser verdadeiro e racional.

É estreme de dúvidas que a falta do uso de evidência na medicina e de aperfeiçoamento da pesquisa clínica impacta forte e significativamente na judicialização da saúde. De outro lado, vislumbra-se que, a despeito da necessidade do uso do clinical trial, sua utilização aliada ao tempo de maturação pode não se revelar adequada e suficiente para o enfrentamento da judicialização. Nesse contexto, pareceu e parece que o compartilhamento de riscos aliado à processualística, notadamente no bom uso do regime de tutelas de urgência, pode ser instrumento menos custoso e, a curto prazo, mais eficaz para o enfrentamento da judicialização da saúde.

\section{Proposta para enfrentamento da judicialização da saúde}

José Renato Nalini publicou um artigo intitulado Quem se arriscará na gestão pública? (8) e suas proposições e conclusões são tão contundentes quanto, desafortunadamente, de 
fácil constatação. Suas críticas, por mais que seja duro admitir, são adequadas à estrutura estatal atual e, especificamente, ao Sistema Único de Saúde (SUS).

Nalini trata da amplitude do Texto Constitucional; da consequente interferência na gestão; e da "aventura" que se tornou ser um gestor público. Aborda, outrossim, a judicialização da atividade administrativa na "República dos direitos e da hermenêutica", onde "todas as interpretações são possíveis" (8).

Tudo isso é sentido na estrutura do SUS: houve promessa de uma quantidade um tanto quanto maior do que a capacidade do Estado; as interpretações vão mais além do já se prometeu de modo pouco responsável; e a desestruturação, nesse contexto, incrementase.

Já se percebe, ainda que de modo tímido, alguma reflexão em torno do que cabe ao Estado. A medicina baseada em evidências se revela como caminho a ser seguido, entretanto, não a curto prazo. Como se viu, o trabalho para a busca da melhor evidência é árduo e custoso; e a necessidade de se prover saúde de modo minimamente abalizado e responsável não pode esperar tanto, seja pelo lado do paciente, seja pelo lado dos gestores, seja pela perspectiva do próprio Estado.

Nesse diapasão, já se tem tratado de um compartilhamento de riscos e assunção de responsabilidade pelos atores participantes dessa cena (4). Aliás, o artigo $5^{\circ}$ do CPC determina que "aquele que de qualquer forma participa do processo deve comportar-se de acordo com a boa-fé" (2). A propósito do compartilhamento de riscos, importante que se reporte à Portaria GM no 1.297, de 11 de junho de 2019, do Ministério da Saúde, que

\begin{abstract}
"institui projeto piloto de acordo de compartilhamento de risco para incorporação de tecnologias em saúde, para oferecer acesso ao medicamento Spinraza (Nusinersena) para o tratamento da Atrofia Muscular Espinhal (AME 5q) tipos II e III no âmbito do Sistema Único de Saúde - SUS".
\end{abstract}

Clenio Schulze, juiz federal, que tem se notabilizado pelo estudo da judicialização da saúde, ocupou-se de noticiar o tema por meio de breve escrito com o título de "Direito à saúde e compartilhamento de risco (9).

Do que se tem, de fato, até hoje, pode até se pensar que os protocolos que têm sido 
produzidos e os convênios entre universidades e as cortes de justiça são suficientes. Com o respeito devido, não são. O produtivismo quantitativo que assola o Judiciário, em decorrência da avalanche de demandas, generaliza esses protocolos, passando a incrementar a produção em escala que não se baseia, exatamente, em evidências.

Diante desse cenário e de modo mais imediato, o que se pode propor de válido? artigo 297 do CPC assevera que "o juiz poderá determinar as medidas que considerar adequadas para efetivação da tutela provisória" (2), que, em perspectiva sistêmica, deve ser lido em conjunto com o artigo 139 do Código e, mais especificamente, com o inciso IV desse último dispositivo citado, que dispõe que incumbe ao juiz "determinar todas as medidas indutivas, coercitivas, mandamentais ou sub-rogatórias necessárias para assegurar o cumprimento de ordem judicial, inclusive nas ações que tenham por objeto prestação pecuniária" (2).

Com a supervisão que o juiz exerce no processo e em ambiente colaborativo com as partes, na condição de ator do processo, sempre com boa fé, vislumbra-se possível o deferimento de antecipações de tutela de modo fundado, responsável e hábil a conferir tudo aquilo e exatamente aquilo que couber à parte por direito. Assim, poder-se-ia pensar em uma tutela de urgência deferida, mas calibrada, na forma do artigo 297 do CPC (2), adotando o juiz espécie de compartilhamento de riscos, a exemplo do que preconiza a Portaria GM nº 1.297/2019 (4). Em paralelo, em ambiente de colaboração e boa-fé, poderia se exigir dos médicos que prescreveram o fármaco ou insumo medicinal que o substituíssem, caso não fosse atingido o desiderato, implicando-os, também, quando da concessão da medida, haja vista os termos do artigo $5^{\circ}$ do CPC (2).

No congresso do Conasems, fez-se abordagem comparada da judicialização da saúde, com citação das experiências na Inglaterra, na África do Sul e na Alemanha. O que se revelou é que, com efeito, as interpretações no Brasil são por demais elásticas.

É necessário que se altere a cultura na judicialização da saúde posto que se está muito próximo de um colapso irreversível. A perplexidade de gestores qualificados quanto à possibilidade de assunção de cargos importantes e caros às políticas públicas acaba por afastar excelentes quadros da administração pública, tornando o cenário mais pessimista.

O Supremo Tribunal Federal, em exercício de atribuições dignas de olhar atento, tem se debruçado sobre o tema da judicialização da saúde e procurado sistematizar a matéria, 
cônscia aquela Corte de Justiça da gravidade do assunto e da necessidade de não precipitar a inviabilização do prosseguimento das gestões no âmbito das Unidades da Federação. $O$ momento é sobremaneira oportuno e soa como candente exortação à reflexão de todos os atores envolvidos.

\section{À guisa de conclusão}

Parece estreme de dúvidas que se chegou ao limite no que toca ao tema da judicialização da saúde. Os atores envolvidos, mormente os gestores da saúde, têm feito grande esforço no sentido de buscar soluções para a matéria.

Procurou-se demonstrar - a partir de breves noções sobre o regime das tutelas de urgência, da medicina baseada em evidências e da alternativa viável da mescla do uso das tutelas de urgência com a medida do compartilhamento de riscos - que é possível e premente que se altere a cultura em torno da judicialização da saúde e que os pleitos sejam apreciados de modo mais técnico, fundado, mais responsável, pautado em boa fé e, enfim, com observância do que previsto na lei. Não se quer limitar o acesso à jurisdição e ao direito, que, de toda sorte, por disposição constitucional, não ficariam inviabilizados. Deu-se, destarte, sugestão de tutela deferida com calibragem e adotando uma postura de compartilhamento de riscos ou congênere e tomando compromisso dos profissionais envolvidos, como já declinado.

Nada obstante, autorizado magistério doutrinário e cotejado com a experiência internacional, estamos a deferir tudo a todos e sem critério seguro. Não se quer, aqui, voltar à discussão sibilina da reserva do possível. $O$ fato é que estamos a nos aproximar perigosamente de um colapso que pode levar, sim, a um caminho sem volta. Bons profissionais, bons gestores, estão cada vez mais se afastando da atividade administrativa. Os que restam nos quadros da administração pública estão adotando atitudes de absoluta contenção, que são tão deletérias quanto agir de modo desordenado.

Fica, aqui, uma rogativa para que se considere, tal como proposto, uma exortação ao debate. Ao menos isso. Do contrário, talvez o caminho seja mesmo desistir de buscar prover saúde de um modo minimante digno e vocacionado. 


\section{Referências}

1. Brasil. Constituição da República Federativa do Brasil de 1988. Disponível em: http://www.planalto.gov.br/ccivil_03/constituicao/constituicao.htm [Acesso em 20 jul. 2019].

2. Brasil. Lei no 13.105, de 16 de março de 2015. Código de Processo Civil. Disponível em: http://www.planalto.gov.br/ccivil_03/_ato2015-2018/2015/lei//13105.htm [Acesso em 20 jul. 2019].

3. Neto JAC, Sirimarco MT, Guerra MCS, Silva VC, Portela WS, Rocha FRS. Percepção da aplicabilidade da Medicina Baseada em Evidência. Disponível em: https://periodicos.ufj..br /index.php/hurevista/article/view/37/68 [Acesso em 25 ago. 2019].

4. Portaria GM no 1.297, de 11 de junho de 2019. Disponível em: https://www.conass.org.br/ conass-informa-n-97-publicada-a-portaria-gm-n-1297-que-institui-projeto-piloto-de-acordode-compartilhamento-de-risco-para-incorporacao-de-tecnologias-em-saude-para-ofereceracesso-ao-med/ [Acesso em 25 ago. 2019].

5. Brasil. Superior Tribunal de Justiça. AgInt no AREsp no 1442211/GO. Agravante: Celg Distribuição S.A - Celg D. Agravado: Fabio Magnus Ferreira Lauriano Leme. Relator Ministro Marco Aurélio Belizze. Brasília, 17 jun 2019. DJe. Jun 2019.

6. Marinoni LG. O Precedente na Dimensão da Igualdade. Disponível em: http://www.marinoni.adv.br [Acesso em 20 jul. 2019].

7. Pinho HDB. Os princípios e as garantias fundamentais no projeto de Código de Processo Civil: breves considerações acerca dos artigos 1ำ ao 12 do PLS no 166/2010. Revista Eletrônica de Direito Processual - REDP. Volume VI. Periódico da pós-graduação stricto sensu em Direito Processual da UERJ. 2010, 6 (6): 49-92. Disponível em: https://www.epublicacoes.uerj.br/index.php/redp/article/view/21568/15570 [Acesso em 20 jul. 2019].

8. Nalini JR. Quem se arriscará na gestão pública? Disponível em: http://divinews.com/2019/05/07/artigo-quem-se-arriscara-na-gestao-publica/ [Acesso em 20 jul. 2019].

9. Schulze CJ. Direito à saúde e compartilhamento de risco. Disponível em: https://emporiododireito.com.br/leitura/direito-a-saude-e-compartilhamento-de-risco [Acesso em 20 jul. 2019].

Tavares LMC. As tutelas de urgência na judicialização da saúde e a medicina baseada em evidências. Cadernos IberoAmericanos de Direito Sanitário. 2019 jul./set.; 8(3): 178-185. 